\title{
Antioxidant Capacity and Lipophilic Constitution of Alternanthera bettzickiana Flower Extract
}

\author{
A.J.A. PETRUS ${ }^{1 *}$, K. KALPANA and A. BHARADHA DEVI \\ Department of Chemistry, Kanchi Mamunivar Centre for \\ Post-Graduate Studies (Autonomous), Puducherry - 605008, India. \\ *Corresponding author E-mail: ajapetrus @ hotmail.com \\ http://dx.doi.org/10.13005/ojc/300212
}

(Received: February 12, 2014; Accepted: March 04, 2014)

\begin{abstract}
Alternanthera bettzickiana (Regel) Nicolson is an erect herb and an ornamental pot plant, which is recorded to be useful in purifying and nourishing blood. It is also claimed to be a soft laxative, a galactagogue and an antipyretic in addition to its wound healing property. The leaves are reported to be used like spinach and in soups. The lipophilic acetone extract of the fresh flowers exhibited in vitro antioxidant/radical scavenging (ABTS ${ }^{+}$and FRAP assays) and metal (Ferrous ion) chelating capacities. The extract has been analysed to contain eighteen saturated and four unsaturated hydrocarbons, ten saturated, three monounsaturated and one polyunsaturated esters of fatty acid, in addition to a saturated and an unsaturated higher alcohol and a fatty aldehyde, together with a monoterpene and nine acyclic diterpenes and a steroid. $\gamma$-Tocopherol and $\alpha$ tocopherol- $\beta$-D-mannoside are the principal vitamin $E$ identified in combination with pairs of cyclohexenones and benzofuranones as well as five phthalates.
\end{abstract}

Key words: Alternanthera bettzickiana,Amaranthaceae, Antioxidant capacity, Lipophilic constitution, phytometabolites.

\section{INTRODUCTION}

Alternanthera Forsk ${ }^{1,2}$, belonging to the family Amaranthaceae and comprising of ca. 80 species $^{3}$, is a genus of evergreen, perennial herbs that are native to tropical and sub-tropical regions. The taxa occur abundantly in Australia and Tropical America and about nine of them are reported from South India ${ }^{2}$. The leaves of $A$. sessilis (L.) and $A$. bettzickiana (Regel) Nicolson are reported to be used like spinach and in soups ${ }^{4}$. A. brasiliana, $A$. philoxeroides, $A$. pungens, $A$. sessilis and $A$. tenella have been pharmacologically investigated ${ }^{5-13}$ to exhibit antiviral (HSV-1 and HIV), antihistaminic, anticarcinogenic, antileukaemic, antiulcer, antihepatotoxic and diuretic activities. $A$. philoxeroides Griseb is being prescribed clinically in the People's Republic of China for the treatment of viral hepatitis, epidemic parotitis, hemorrhagic fever and influenza. A. sessilis (L.) R. Br. ex DC is 
said to be recommended against fever and also used as a galactogogue. The stem and the leaves are claimed to help in snake-bite and the young shoots are reported to be nutritious ${ }^{14}$.

A. bettzickiana (Regel) Nicolson (syn.Telanthera bettzickiana Regel ${ }^{2}$, is an erect herb and an ornamental pot plant in houses and public gardens. The whole plant is reported to be useful in purifying and nourishing blood and is claimed to be a soft laxative, a galactagogue and an antipyretic, in addition to its wound healing property. The acetone extract has been found to possess lipoxygenase, tyrosinase and xanthine oxidase inhibitory activities ${ }^{15}$. Earlier studies have reported the characterisation of simple and acylated betacyanins from the leaves ${ }^{16}$. The recent understanding of the multiple roles of the diverse array of secondary metabolites (mediated by reduction, reactive species-scavenging and prooxidant metal chelation) by which they protect against the pathogenesis of a number of degenerative disorders ${ }^{17,18}$, has resulted in viewing these food plants as functional foods. Hence, characterisation of the dietary antioxidants present in them and their capacities provide better insight into their functionality, as these dietary constituents are necessary to cope up with the initiation or propagation of the reactive oxidants ${ }^{18}$. In continuation of our investigations on the South Indian species of Alternanthera ${ }^{19}$, the reactive species scavenging and pro-oxidant metal chelating capacities as well as the lipophilic constitution of the fresh flowers of $A$. bettzickiana, collected from the wild habitat, are reported in the present paper.

\section{MATERIALS AND METHODS}

\section{Materials}

Fresh flowers of $A$. bettzickiana, collected from the wild population were extracted using acetone (3x4 L, $48 \mathrm{~h}$, ambient), after establishing the identity of the taxon, and concentrated under reduced pressure to get the lipophilic extract. 2,2'Azinobis(3-ethylbenzothiazoline-6-sulphonic acid) (ABTS) diammonium salt, 2,4,6-tris(2-pyridyl)-striazine (TPTZ), 3-(2-pyridyl)-5,6-di(4phenylsulphonic acid)-1,2,4-triazine (ferrozine) sodium salt, ethanol, ferrous chloride and rutin were obtained from Sigma-Aldrich Inc. All other chemicals/reagents were of analytical/laboratory grades from Himedia/Merck/Loba Chemie. GC-MS was recorded using SHIMADZU QP2010.

\section{METHODS}

\section{Determination of Vitamin C equivalent antioxidant capacity}

ABTS radical cation $\left(\mathrm{ABTS}^{\cdot+}\right)$ scavenging capacity and ferric-reducing/antioxidant power (FRAP) of the lipophilic extract were determined by the procedures described previously ${ }^{20}$ and expressed as Vitamin C equivalent antioxidant capacity (VCEAC). Vitamin $\mathrm{C}$ standard curves were constructed by plotting the absorbances of $1.25,2.5,5,10,15,20,25 \mathrm{mg} / \mathrm{L}$ of L-ascorbic acid against the corresponding concentrations. The VCEAC of the extract of increasing concentrations (50,100, 200, $400 \mathrm{mg} / \mathrm{L})$ and standard rutin $(10 \mathrm{mg} / \mathrm{L})$ were determined from the standard graph and expressed as percentage, as detailed before. All data were recorded as mean $\pm S D$, computed from three replications.

\section{Determination of Transition metal ion chelating capacity}

Pro-oxidant metal chelating capacities of the lipophilic extract/standard were evaluated using $\mathrm{Fe}^{\mathrm{Il}}$ and the percentage inhibition of the ferrozine$\mathrm{Fe}^{\|}$complex formation was calculated adopting the protocol described earlier ${ }^{18,20}$, in triplicate. The ubiquitous flavonoid rutin was used as positive standards as before.

\section{Separation and Identification of the lipophilic metabolites}

GC-MS was recorded using a SHIMADZU QP2010 gas chromatographic system, equipped with a split injection port, a flame ionization detector and a GC-MS solution version 2.53 software. Column: $30.0 \mathrm{~m} \times 0.25 \mathrm{~mm}, 0.25$ ìm capillary column (100\% Dimethylpolysiloxane) and carrier gas: $\mathrm{He}$ (99.9995\% purity) at $1.50 \mathrm{~mL} / \mathrm{min}$ with a split ratio of 10:1. Injector and detector temperatures maintained at $260^{\circ} \mathrm{C}$. Oven temperature: initially at $70^{\circ} \mathrm{C}$ for $2 \mathrm{~min}$. and increased to $300^{\circ} \mathrm{C}$ at a rate of $5^{\circ} \mathrm{C} / \mathrm{min}$. Mass spectra were recorded at $70 \mathrm{eV}$ with scan range of $40-1000 \mathrm{~m} / \mathrm{z}$. Interpretation of mass spectra were made using the databases of National Institute Standard and Technique (NIST08s), WILEY8 and FAME. 


\section{RESULTS AND DISCUSSION}

\section{Determination of in vitro antioxidant capacity} Oxidative stress is created when there is an imbalance between the generation of reactive species and their quenching. Oxidative stress due to high flux of oxidants has been implicated in the pathogenesis of several modern human ailments ${ }^{20}$. Antioxidant protection against damages that could be caused by free radicals is vital for the integrity of cellular structures and macromolecules. All plants synthesise a vast array of chemical compounds that are not necessarily involved in the plant's metabolism but instead serve a variety of functions that enhance the plant's survivability, including their ability to combat oxidative stress. A number of these bioactive exogenous dietary antioxidants have been demonstrated to be effective in preventing reactive species-mediated damages and the consequent chronic disease states ${ }^{18,20}$. Food industries are also concerned with oxidative processes since lipids, the natural constituents of cellular membranes, are oxidised during peroxidation, producing partial or total changes in food sensorial properties and in nutritional values. Plant-based antioxidants and colourants are the order of the day to preserve food quality because of safety concerns. In the recent past, there have been growing interests in functional foods, which not only offer the basic nutrition and energy, but also added physiological benefits to the consumers. The functionality of a food usually has a close relationship with some of its ingredients and those ingredients that could be derived from food/natural sources are preferred over synthetic ones, whose applications are restricted due to suspected harmful health effects. Characterisation of the dietary antioxidants and their capacities are also essential to validate the safety and traditional uses and to standardise preparations of these plants. As a result, widespread screening of medicinal and food plants with antioxidant potentials has become a common practice.

The acetone extract of $A$.bettzickiana has been recorded to possess lipoxygenase, tyrosinase and xanthine oxidase inhibitory activities ${ }^{15}$. Consequently, the fresh flowers of A.bettzickiana (Fig. 1) were extracted with acetone at ambient temperature for $48 \mathrm{~h}$, concentrated at $40 \pm 2^{\circ} \mathrm{C}$ to get the lipophilic extract. The antioxidant capacity has been evaluated based on the measurement of the capacities of increasing concentrations of the extract (i) to scavenge stable ABTS ${ }^{*}$ radicals, (ii) to reduce $\mathrm{Fe}^{\mathrm{III}}$ to $\mathrm{Fe}^{\text {"l }}$ and (iii) to inhibit $\mathrm{Fe}^{\prime \prime}$-ferrozine complex formation. The most commonly employed assay of antioxidant capacity measurements is the one that involves the generation of the coloured radical cationic oxidant $\mathrm{ABTS}^{\circ+}$ and determining the ability of an extract/a metabolite to scavenge the same $^{21}$. Since ABTS ${ }^{+}$is soluble in both aqueous and organic phases and is not affected by ionic strength, it is capable of reacting with both lipophilic and hydrophilic metabolites. The extract scavenged the radicals dose-dependently, even though it possessed only $57.43 \%$ of the VCEAC of the standard rutin at the highest concentration, namely $400 \mathrm{mg} / \mathrm{L}$ (Table 1). The FRAP assay also measured the antioxidant capacity to vary linearly with the concentrations and was found to have $47.8 \%$ of

Table 1. Reactive species scavenging and Ferrous ion chelating capacities of $A$. bettzickiana lipophilic flower extract

\begin{tabular}{|c|c|c|c|c|}
\hline \multirow[t]{3}{*}{ Analyte } & \multirow{3}{*}{$\begin{array}{l}\text { Concentration } \\
(\mathrm{mg} / \mathrm{L})\end{array}$} & \multicolumn{3}{|c|}{ Relative Percentage ${ }^{a}$} \\
\hline & & \multicolumn{2}{|c|}{ VCEAC } & \multirow{2}{*}{$\begin{array}{l}\mathrm{Fe}(\mathrm{II}) \\
\text { Chelation }\end{array}$} \\
\hline & & ABTS & FRAP & \\
\hline Lipophilic & 50 & $10.4 \pm 0.3$ & $8.6 \pm 0.5$ & $21.4 \pm 0.7$ \\
\hline \multirow[t]{3}{*}{ Extract } & 100 & $18.7 \pm 0.8$ & $14.4 \pm 0.4$ & $35.6 \pm 1.2$ \\
\hline & 200 & $30.1 \pm 1.6$ & $25.2 \pm 1.1$ & $52.3 \pm 2.2$ \\
\hline & 400 & $48.3 \pm 1.5$ & $38.5 \pm 1.6$ & $68.7 \pm 0.8$ \\
\hline Rutin & 10 & $84.1 \pm 2.4$ & $80.6 \pm 3.1$ & $72.9 \pm 1.6$ \\
\hline
\end{tabular}

${ }^{a}$ Mean \pm standard deviation $(n=3)$ 
Table 2: Lipophilic constitution of $A$. bettzickiana flowers

\begin{tabular}{|c|c|c|c|c|}
\hline Compound & & $\#$ & Rt & Peak area \\
\hline 1 & Tetradecane & 5 & 10.580 & 4866768 \\
\hline 2 & Hexadecane & 16 & 13.057 & 7492617 \\
\hline 3 & Octadecane & 24 & 15.285 & 4946679 \\
\hline 4 & Eicosane & 38 & 17.355 & 2821134 \\
\hline 5 & Tetracosane & 48 & 21.155 & 900282 \\
\hline 6 & Pantacosane & 64 & 26.467 & 14931855 \\
\hline 7 & Heptacosane & 53 & 23.515 & 3198293 \\
\hline 8 & Octacosane & 63 & 26.151 & 10826544 \\
\hline 9 & Nonacosane & 59 & 24.931 & 9056357 \\
\hline 10 & Tetratriacontane & 51 & 22.764 & 364711 \\
\hline 11 & 5-Methyltetradecane & 13 & 12.486 & 412731 \\
\hline 12 & 3-Methyltetradecane & 14 & 12.712 & 809771 \\
\hline 13 & 3-Methylheptadecane & 22 & 14.978 & 625702 \\
\hline 14 & 2-Methylheptadecane & 46 & 20.923 & 225445 \\
\hline 15 & 5-Butylnonane & 2 & 8.987 & 1187747 \\
\hline 16 & 9-Ethyl-9-n-heptyloctadecane & 55 & 23.966 & 316146 \\
\hline 17 & 3,5,23-Trimethyltetracontane & 9 & 11.828 & 2220585 \\
\hline 18 & 3,5,24-Trimethyltetracontane & 61 & 25.460 & 1115753 \\
\hline 19 & 1-Tetradecene & 4 & 10.481 & 1014929 \\
\hline 20 & 1- Hexadecane & 15 & 12.969 & 942787 \\
\hline 21 & 1-Nonadecene & 23 & 15.213 & 722763 \\
\hline 22 & 1-Methyl-1-tetradecene & 21 & 14.480 & 819147 \\
\hline 23 & Methyldodecanoate & 10 & 12.154 & 1286351 \\
\hline 24 & Methylpalmitate & 33 & 16.602 & 14065962 \\
\hline 25 & Methylstearate & 42 & 18.662 & 1104505 \\
\hline 26 & Methylicosanoate & 44 & 20.550 & 461677 \\
\hline 27 & Methylbehenate & 49 & 22.233 & 1307049 \\
\hline 28 & Methyltricosanote & 52 & 23.013 & 450734 \\
\hline 29 & Methyllignocerate & 54 & 23.757 & 624791 \\
\hline 30 & Isopropylhexadecanoate & 43 & 20.251 & 191806 \\
\hline 31 & Ethylpalmitate & 37 & 17.296 & 1638189 \\
\hline 32 & Cyclohexylpalmitate & 47 & 20.993 & 344521 \\
\hline 33 & Methylelaidate & 40 & 18.414 & 1956366 \\
\hline 34 & Methyl-cis-12-octadecenoate & 41 & 18.472 & 777620 \\
\hline 35 & Methylnervonate & 56 & 24.012 & 369710 \\
\hline 36 & Methyllinoleate & 39 & 18.358 & 5799387 \\
\hline 37 & 2-Hexyl-1-octanol & 3 & 10.189 & 1209413 \\
\hline 38 & (2E)-2-Tetradecen-1-ol & 19 & 14.203 & 875559 \\
\hline 39 & 1-Tetradecanal (Myristylaldehyde) & 20 & 14.381 & 586873 \\
\hline 40 & 1,3,3-trimethyl-2-oxabicyclo[2.2.2]octane (1,8-Cineole) & 7 & 11.384 & 562439 \\
\hline \multirow[t]{2}{*}{41} & $(2 \mathrm{E}, 6 \mathrm{E})-3,7,11$-Trimethyl-2,6,10-dodecatrien-1-ol & & & \\
\hline & (Farnesol) & 11 & 12.241 & 550559 \\
\hline 42 & 3,7,11- Trimethylpentadecan-2-en-1-ol & 30 & 16.163 & 1192539 \\
\hline 43 & 3,6,10,14-Tetramethylpentadecan-2-en-1-ol & 28 & 15.974 & 1196852 \\
\hline 44 & 3,7,11,15-Tetramethylhexadecan-1-ol (Dihydrophytol) & 17 & 13.927 & 388105 \\
\hline 45 & (2E)-3,7,11,15-Tetramethyl-2-hexadecen-1-ol (Phytol) & 31 & 16.261 & 1192198 \\
\hline
\end{tabular}




\begin{tabular}{|c|c|c|c|c|}
\hline \multirow{3}{*}{$\begin{array}{l}46 \\
47\end{array}$} & 3,7,11,15-Tetramethyl-1-hexadecen-3-ol (Isophytol) & 34 & 16.846 & 10425228 \\
\hline & 3-Methylene-7,11,15-trimethyl-1-hexadecene & & & \\
\hline & (Neophytadiene) & 26 & 15.714 & 3214724 \\
\hline \multirow[t]{2}{*}{48} & (6E)-6,10-Dimethyl-5,9-undecadien-2-one (Geranyl & & & \\
\hline & acetone) & 6 & 11.298 & 581180 \\
\hline \multirow[t]{2}{*}{49} & 6,10,14,-Trimethylpentadecan-2-one (Hexahydrofarnesy & & & \\
\hline & acetone) & 27 & 15.777 & 10829732 \\
\hline 50 & Ergost-7-en-3-ol & 62 & 25.648 & 1731027 \\
\hline 51 & 3-Methylphenol & 1 & 6.108 & 24357443 \\
\hline 52 & 2,3-Dimethylphenol & 25 & 15.398 & 512614 \\
\hline 53 & 3-Tocopherol & 58 & 24.676 & 15142652 \\
\hline 54 & \pm -Tocopherol-2-D-mannoside & 60 & 25.372 & 858467 \\
\hline \multirow[t]{2}{*}{55} & (3E)-4-(2,6,6-Trimethyl-1-cyclohexen-1-yl)- & & & \\
\hline & 3-buten-2-one & 8 & 11.771 & 2153452 \\
\hline \multirow[t]{2}{*}{56} & 2,4,4-Trimethyl-3-[(1E)-3-oxo-1-butenyl]-2-cyclohexen- & & & \\
\hline & 1-one & 18 & 13.975 & 442306 \\
\hline \multirow[t]{2}{*}{57} & 4,4,7a- Trimethyl-5,6,7,7a-tetrahydro-1-benzofuran & & & \\
\hline & $-2-(4 \mathrm{H})$-one & 12 & 12.384 & 2606569 \\
\hline \multirow[t]{2}{*}{58} & 3,6-Dimethyl-5,6,7,7a-tetrahydro-1-benzofuran- & & & \\
\hline & $2-(4 \mathrm{H})-o n e$ & 45 & 20.837 & 1342797 \\
\hline 59 & 1,2-Benzenedicarboxylic acid (Phthalic acid) & 32 & 16.539 & 1645250 \\
\hline 60 & Dibutylphthalate & 35 & 17.029 & 4126463 \\
\hline 61 & Diisobutylphthalate & 29 & 16.054 & 1408793 \\
\hline 62 & Mono-2-ethylhexylphthalate & 50 & 22.426 & 9851493 \\
\hline 63 & Butyl-2-ethylhexylphthalate & 36 & 17.243 & 1373311 \\
\hline
\end{tabular}

\# Peak number in the GC-Mass Spectrum (Fig. 1)

the rutin VCEAC at $400 \mathrm{mg} / \mathrm{L}$ (Table 1). The per cent $\mathrm{Fe}^{\text {ll }}$ chelating capacities of the extract was found to be encouraging with $94.2 \%$ as efficient as the standard (Table 1). Considerable evidence has emerged from clinical studies to show that increases in cellular free iron concentrations have been associated with oxidative stress and that genetic and non-genetic iron misregulations in the brain contribute to neuronal death in certain neurodegenerative disorders ${ }^{18}$. Even mildly elevated iron levels have been linked to increased cardiovascular disease and cancer incidences in humans and hence should be maintained within the optimum level. Moreover, in chronic anaemia associated with iron overload such as thalassemia major, Fe-chelating therapy is the only method available for preventing early death, caused predominantly by myocardial and hepatic iron toxicity or to prevent endocrinal abnormalities like diabetes and hypothyroidism. Persuasive epidemiological evidences, today, have brought to light that regular intake of bioactive dietary phytometabolites promises a wide range of benefits, including the regulation of transition metals such as iron.

\section{Separation and Identification of the lipophilic metabolites}

The acetone extract of A.bettzickiana has been further subjected to GC-MS analysis (Fig. 2) to analyse its chemical composition. The phytometabolites, belonging to various chemical classes (Fig. 3 and 4), that have been identified from the lipophilic fraction are tabulated (Table 2). Eighteen saturated ${ }^{1-18}$ and four unsaturated ${ }^{19-22}$ hydrocarbons, ten saturated ${ }^{23-32}$, three monounsaturated ${ }^{33-35}$ and one polyunsaturated ${ }^{36}$ esters of fatty acid, including a cyclohexyl derivative $^{32}$, in addition to a saturated ${ }^{37}$ and an unsaturated $^{38}$ higher alcohol and a fatty aldehyde ${ }^{39}$ have been identified. A monoterpene ${ }^{40}$ and nine acyclic diterpenes ${ }^{41-49}$, together with a phytosterol, ergost-7-en-3-ol (24-Methyl-5- $\beta$-cholest-7-en-3- $\beta$ ol) [50] were also resolved. Phytosterols are the 
cholesterol homologues and it is reported that lowdoses of phytosterol-supplementation has produced significantly lowered plasma total cholesterol 22 . Such lipid-lowering effect of phytosterols is claimed to be mediated by competitive inhibition of cholesterol absorption and by transcriptional induction of genes implicated in cholesterol metabolism in both enterocytes and hepatocytes. The reduced absorption stimulates

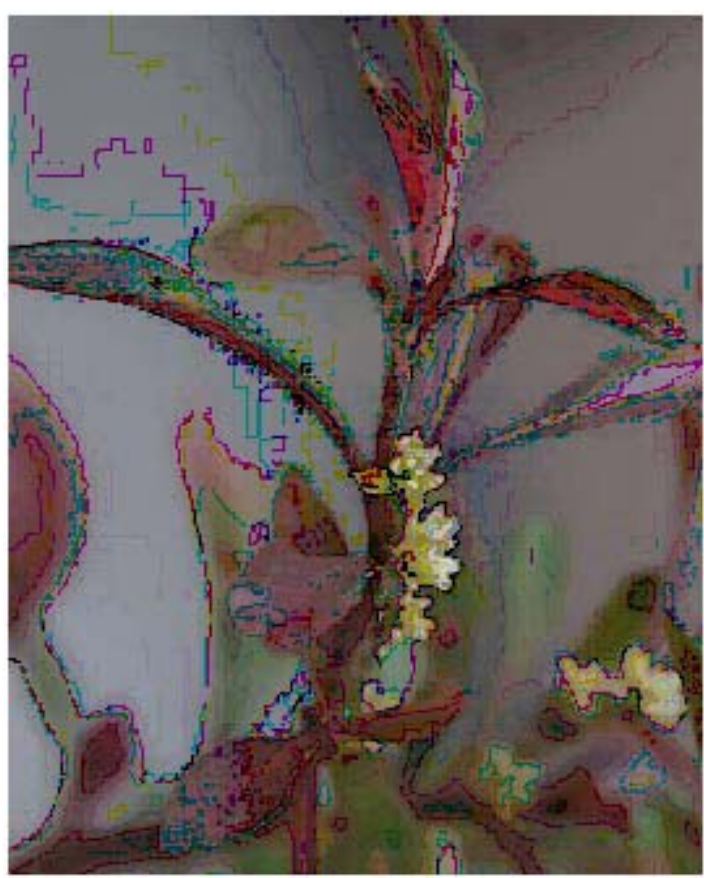

Fig. 1: A. bettzickiana twig with flowers
LDL-receptor formation, which, in turn, increases the hepatic uptake of LDL and thus decreases LDL levels ${ }^{23}$. Though the biological and ecochemical functions of terpenes have not been fully investigated yet, plants generally produce volatile terpenes in order to attract specific insects for pollination, to protect the plants from herbivores that feed on these plants, and also play an important role as signal compounds and growth regulators. Less volatile but strongly bitter-tasting or toxic terpenes also act as antifeedants.

The most abundant class of bioactive dietary metabolites are the biophenols ${ }^{24}$, which are the extremely important components of the human diet with both nutritional and medicinal benefits reported for animals and humans, mediated largely by their redox property, free radical scavenging capacity and the ability to mitigate oxidative stressinduced tissue damage associated with chronic diseases. They also exhibit a remarkably diverse range of bio-physicochemical properties that makes them rather unique and intriguing natural products. Among the scores of reasons for their everincreasing recognition, not only by the scientific community but also by the general public, is their capacity to scavenge oxidatively generated free radicals. Tocochromanols ${ }^{24}$, which are the lipidsoluble dietary antioxidants, that belong to vitamin E group are the interesting biophenols identified in the present study. $\gamma$-Tocopherol [53], is the major

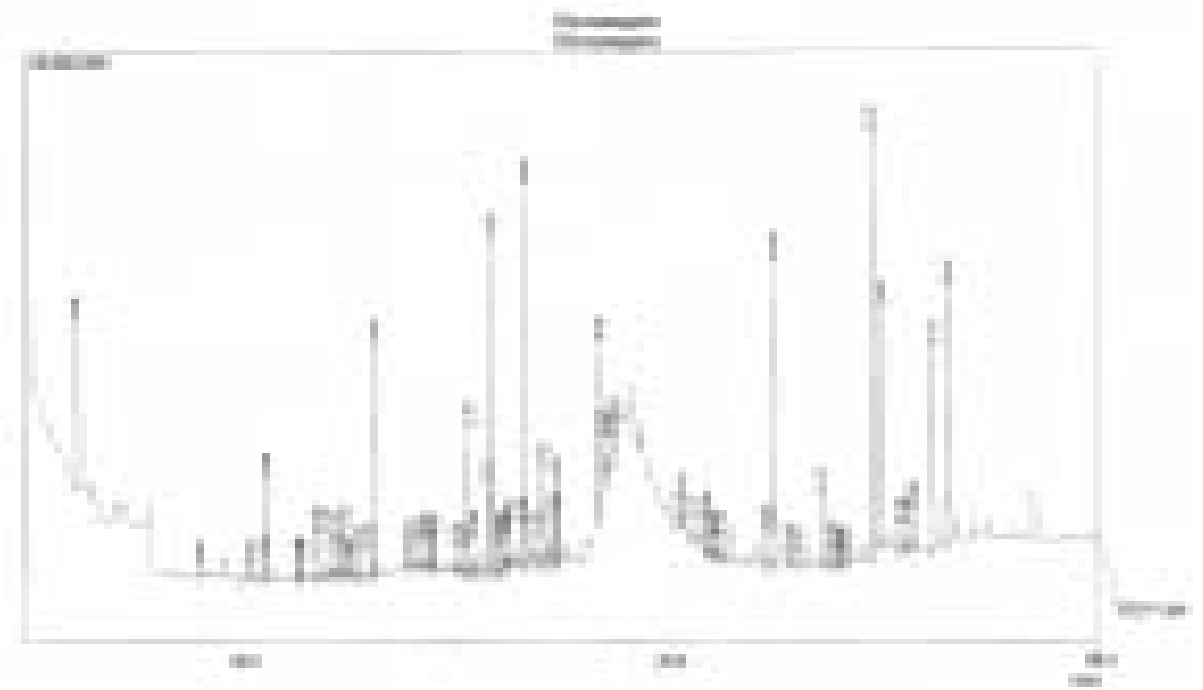

Fig. 2: Gas chromatogram of the lipophilic extract of $A$. bettzickiana flowers 
tocopherol in circulation and has been found to be an unique antioxidant that protects cells from damages associated with nitrogen-based oxidants $^{23} \gamma$-tocopherol is also reported to act as an antiinflammatory agent and may, therefore, reduce long-term damages to cells. This vitamin $E$ component is found to co-exist with its analogue, $\alpha$-tocopherol- $\beta$-D-mannoside [54]. Their antioxidant

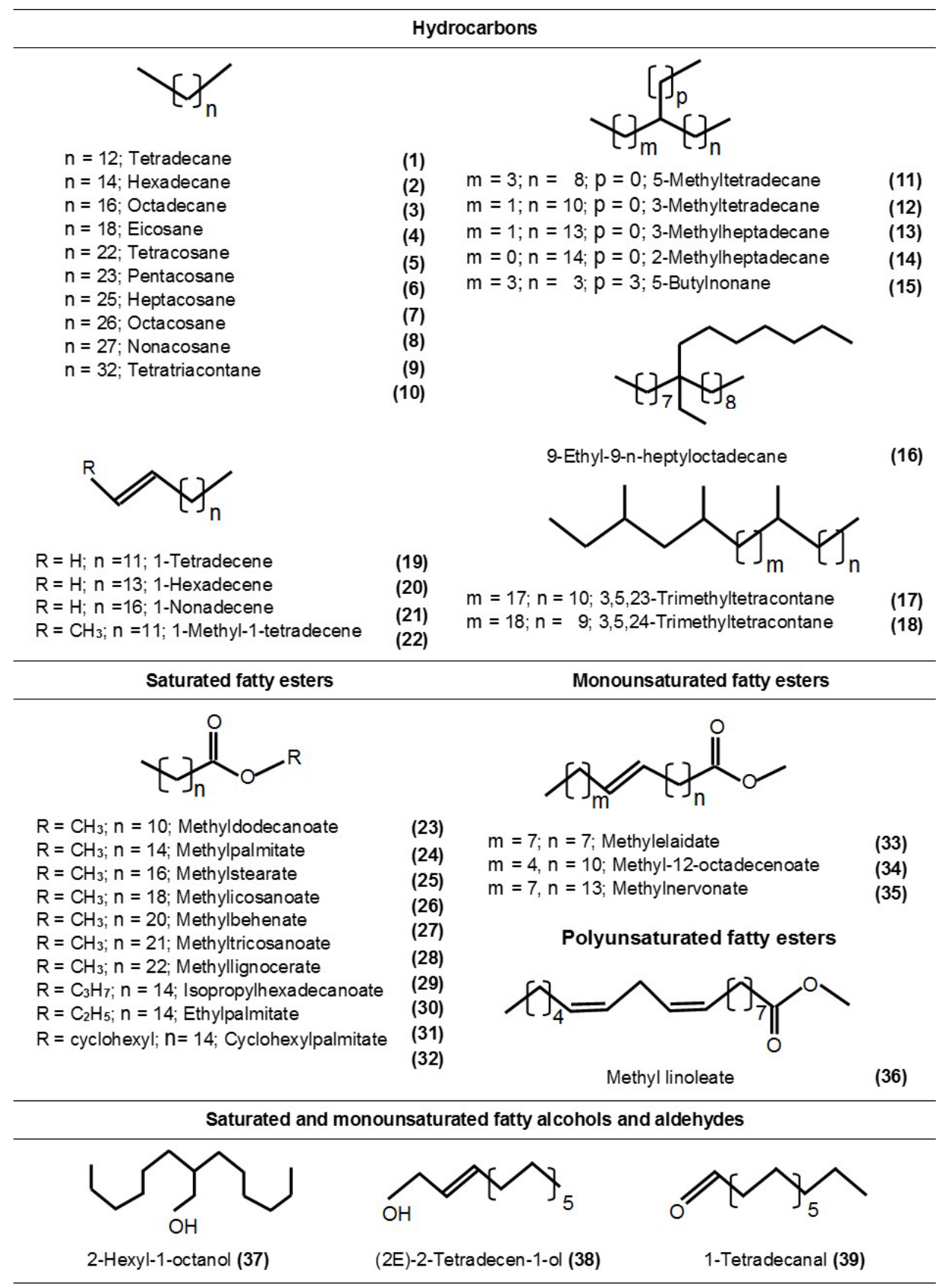

Fig. 3: Certain lipophilic classes of metabolites identified 
activity has been attributed to the capacity of their heterocyclic chromanol ring system to donate the phenolic hydrogen to lipid free radicals ${ }^{24}$. The other classes of phytometabolites identified include the pairs of cyclohexenones [55-56], and benzofuranones [57-58] as well as the five phthalates [59-63].

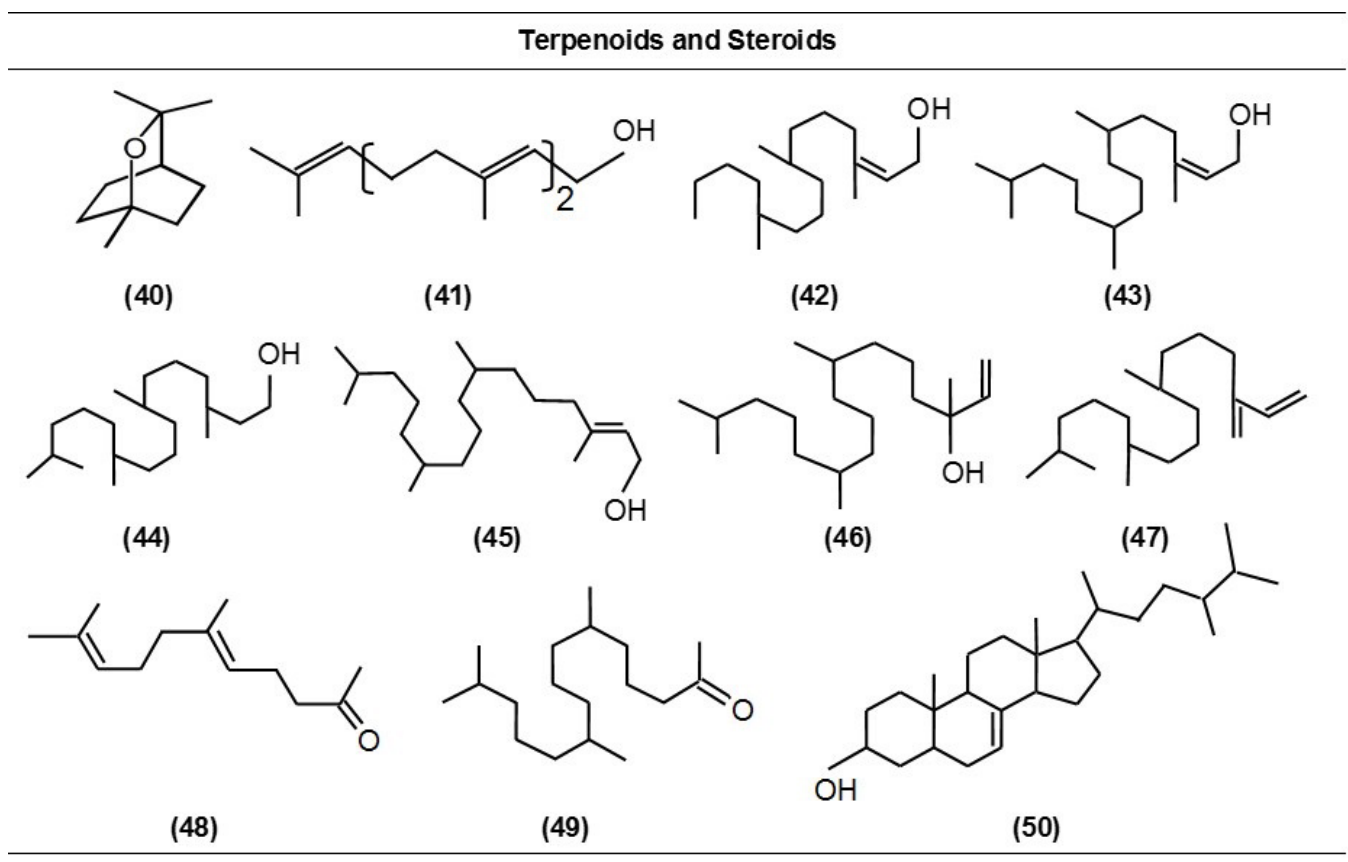

Biophenols, Cyclohexenones, Furanones and Phthalates<smiles>[R]c1cccc(O)c1[R]</smiles>

$\mathrm{R}^{1}=\mathrm{H} ; \mathrm{R}^{2}=\mathrm{CH}_{3} ; 3-$ Methylphenol (51)

$\mathrm{R}^{1}=\mathrm{R}^{2}=\mathrm{CH}_{3} ; 2,3$-Dimethylphenol

(52)<smiles>CC(=O)/C=C/C1=C(C)CCCC1(C)C</smiles>

(55)<smiles>CC(=O)/C=C/C1=C(C)C(=O)CCC1(C)C</smiles>

(56)<smiles>[R]Oc1c([R])c(C)c2c(c1[R])OC(C)(CCCC(C)C)CC2</smiles>

$\mathrm{R}^{1}=\mathrm{CH}_{3} ; \mathrm{R}^{2}=\mathrm{R}^{3}=\mathrm{H} ; \gamma$-Tocopherol

(53) $R^{1}=R^{2}=C_{3} ; R^{3}=\beta$-D-mannose; $\alpha$-Tocopherol- $\beta$-D-mannoside

(54)<smiles>CC1(C)CCC[C@]2(C)OC(=O)C=C12</smiles>

(57)<smiles>CC1=C2CCC(C)CC2OC1=O</smiles>

(58)<smiles>[R]OC(=O)c1ccccc1C(=O)O[R]</smiles>

$\mathrm{R}=\mathrm{R}^{1}=\mathrm{H}$

$\mathrm{R}=\mathrm{R}^{1}=\left(\mathrm{CH}_{2}\right)_{3}-\mathrm{CH}_{3}$

$\mathrm{R}=\mathrm{R}^{1}=\mathrm{CH}_{2}-\mathrm{CH}-\left(\mathrm{CH}_{3}\right)_{2}$

$\mathrm{R}=\mathrm{CH}_{2}-\mathrm{CH}\left(\mathrm{C}_{2} \mathrm{H}_{5}\right)-\left(\mathrm{CH}_{2}\right)_{3}-\mathrm{CH}_{3} ; \mathrm{R}^{1}=\mathrm{H}$

$\mathrm{R}=\left(\mathrm{CH}_{2}\right)_{3}-\mathrm{CH}_{3} ; \mathrm{R}^{1}=\mathrm{CH}_{2}-\mathrm{CH}\left(\mathrm{C}_{2} \mathrm{H}_{5}\right)-\left(\mathrm{CH}_{2}\right)_{3}-\mathrm{CH}_{3}$

Fig. 4: Biologically significant classes of metabolites identified 


\section{CONCLUSION}

Studies of the recent past decades have substantiated that increased consumption of wild sources of fruits and vegetables reduce the risk of chronic diseases including cardio- and cerebrovascular diseases, certain forms of cancer, hypertension, type 2 diabetes and stroke, worldwide. The protection is due, largely, to the plethora of bioactive metabolites, both nutritive and nonnutritive, biosynthesised by these food plants. Consequently, the focus of nutrition research, today, is heading towards the concept of 'Preventive Medicine', and experts have predicted that nutrition will become the primary and the only accessible and the most affordable treatment modality in the 21 st century. Hence, as a part of the continuing exercise, we have analysed and reported the antioxidant capacity and the composition of the lipophilic extract of the fresh flowers of the functional food plant, A. bettzickiana.

\section{ACKNOWLEDGEMENTS}

The authors are grateful to Sargam Laboratory Private Limited (Bureau Veritas Consumer Product Services (I) Pvt. Ltd.), Chennai, India, for the analytical facilities.

\section{REFERENCES}

1. Kumari G.R. In: Henry A.N., Kumari G.R. and Chitra V. (eds.), Flora of Tamil Nadu, India, Series I: Analysis, Vol.2 Botanical Survey of India, Coimbatore, India, 1987; 189.

2. Reddy, M. H.; Raju R. R. V. J. Econ. Tax. Bot. 1997, 21, 577-586.

3. Salvador, M. J.; Dias D. A. Biochem. System. Ecol. 2004, 32, 107-110.

4. Anonymous, The Wealth of India, Vol.I:A (Revised), PID (NISCOM), New Delhi, India, p. 206: (1985).

5. Ali, A. M.; Mackeen, M. M.; El-Sharkawy, S. H.; Hamid, J. A.; Ismail, N. H.; Ahmad, F. B. H.; Lajis, N. H. Pertanika J. Trop. Agric. Sci., 1996,19, 129-136.

6. Calderón, C. P.; Aseff, S. B. G.; Fuentes, L. B. Phyother. Res., 1997, 11, 606-608.

7. De Souza, M. M.; Kern, P.; Floriani, A. E. O.; Cechinel-Filho, V. Phytother. Res. 1998, 12, 279-281.

8. Garcia S. B.; Calderon, C. P.; Fuents, L. B. Fitoterapia 1995, 66, 324-327.

9. Lagrota, M. H. C.; Wigg, M. D.; Miranda, M. M. F. S.; Santos, M. G. M.; Costa S. S. Biomed. Lett. 1995, 51, 127-135.

10. Macedo, A. F.; Barbosa, N. C.; Esquibel, M. A.; Souza, M. M.; Cechinel-Filho, V. Pharmazie 1999, 54, 776-777.

11. Niu, R. Chin. J. Integ. Trad. West. Med., 1986, 6, 29.
12. Zavala, M. A.; Perez, S.; Perez, C.; Vargas, R.; Perez, R. M., J. Ethnopharmacol. 1998, 61, 41-47.

13. Zhang, S.M.; Tabba, H. D.; Smith, K. M. Chinese Med. J. 1988, 101, 861-870.

14. Chaterjee A. and Pakrashi S.C. Treatise on Indian Medicinal Plants, Vol.1, PID (NISCOM), CSIR, New Delhi, India, 1991; 72.

15. Chen, C.-H.; Chan, H.-C.; Chu, Y.-T.; Ho, H.Y.; Chen, P.-Y.; Lee, T.-H.; Lee, C.-K. Molecules 2009, 14, 2947-2958.

16. Cai,Y.; Sun, M; Corke, H. J. Agric. Food Chem. 2001, 49, 1971-1978.

17. Petrus, A. J. A. Asian J Chem. 2011, 23, 30143020.

18. Petrus, A. J. A.; Bhuvaneshwari, N. Asian J. Chem. 2012, 24, 1261-1267.

19. Petrus, A. J. A.; Seetharaman, T.R. Indian J. Pharm. Sci. 2005, 67, 187-193.

20. Petrus, A. J. A.; Siva Hemalatha, S.; Suguna, G. J. Pharm. Sci. \& Res. 2012, 4, 1856-1861.

21. Petrus, A. J. A. Asian J Chem. 2011, 23, 857862.

22. Calpe-Berdiel, L.; Escola-Gil, J.C.; BlancoVaca, F. Atherosclerosis 2009, 203, 18-31.

23. Petrus, A. J. A. Phcog. J. 2012, 4(34), 1-12. doi: 10.5530/pj.2012.34.1

24. Petrus, A. J. A. Asian J Chem. 2014, 26, Article in press. 